\title{
About the Effectiveness of the Open Horizontal Drains of the Ararat Valley
}

\author{
NG Aloyan* \\ National Agrarian University of Armenia, Armenia \\ *Corresponding author: NG Aloyan, National Agrarian University of Armenia, Armenia
}

Received: 跲February 28, 2019

Published: 紫 March 13, 2019

\begin{abstract}
The article considers the ameliorative condition of the Ararat valley. It presents the main sources that feed the local ground waters, as well as the annual regime variations of these groundwater levels on the areas of the adjacent irrigated and saline lands, and fish farm ponds. The author indicates the role of the horizontal drains in formation of these regimes, and the factual data prove their regular cleaning necessity. Suggestions are given for partial and fundamental improvement of the valley ameliorative condition.
\end{abstract}

Keywords: Waterlogging; Ground Waters; Manholes; Drain; Backwater; Salinization; Productivity

\section{Introduction}

Currently, the RA government is undertaking a number of measures in order to draw the agriculture in the republic out of unfavorable conditions, and to provide its future development which in its turn will help to increase the population standard of living and control inflation. In the Republic of Armenia, where the land resources are extremely limited, the development of agricultural production is generally possible by increasing soil fertility and providing high crop yield. One of the main prerequisites to reach the goal is a favorable, ameliorative condition of the cultivated plots. The mentioned is mainly addressed to the Ararat valley which is the Republic's fundamental storehouse of agricultural products. Favorable nature and climatic conditions in case of appropriate implementation of agro technical and irrigation works allow to get high and sustainable crop yields.

\section{Materials and Methods}

The Ararat valley is a region of totally irrigated agriculture. According to 2016 data $[1,2]$ in this zone, agricultural crops occupy 80918 ha irrigated area, 18358 ha out of which is in unfavorable ameliorative conditions. Besides, the lands situated on 16377 ha of this area are waterlogged, and on the rest area they are also alkaline some extent. The observations performed in the Ararat valley, as well as the world practice, have shown that even in case of $2.5 \mathrm{~m}$ less deep groundwater level the yield of some crops decreases by
$25 \%$, and in case of $1.5 \mathrm{~m}$ less - by 50 and more percent. The high level of ground waters in the Ararat valley causes considerable harm also to the settlements. The greater anxiety is caused by the fact that the area of the plots situated on the territory where the groundwater level is up to $1.0 \mathrm{~m}$ depth makes considerable percent among the total waterlogged lands, particularly, according to the average vegetation data of January 1, 2014, it made 2100 ha. The ground waters of the Ararat valley feed from the subterranean waters coming from premountain regions. This feeding is assisted also by the Araks River and its tributaries (the Sevjur, the Kasakh, the Hrazdan, the Azat, and the Vedi). Other, more powerful and basic feeding source of the groundwater are confined waters of sub artesian aquifer [3]. The water turnover of the ground aquifer with the aquifer that situated below takes place through the chestnut and relatively water-resistant lake aquifer: in upward unloading way and through hydrogeological windows $[4,5]$.

The feeding process of the valley groundwater is also assisted by atmospheric precipitations, and in vegetation period, filtration waters from irrigation systems, and surplus waters that originated due to unregulated irrigation, etc. The regime of the Ararat valley groundwater is also affected by a number of natural and artificial factors which condition their regime spacetime changes. The natural factors are climatic, geomorphological, hydrogeological, geological, and biogenic, including the fact that 
the valley has extremely small self-draining ability. The artificial factors include water catchment structures, drainage and irrigation systems, different types of artificial backwaters, fish farm ponds, technologically wrongly built flowing wells [5]. To lower the level of groundwater in the Ararat valley, there, in different years, on 20.6 thousand hectares open and closed drain systems were built, the total length of which makes $1667 \mathrm{~km}$, that includes $1036 \mathrm{~km}$ open ones, and $631 \mathrm{~km}$ closed ones. In order to drain the marshes originated downstream the valley rivers, and thus, to eliminate the malaria hotspots, still in 1947, there were built open drains the total length of which, excluding that of water catchment collector system, makes $649 \mathrm{~km}$. Proceeding from the initial purpose, those drains were embedded not deep (1.5m from ground surface), at rather a long spacing $(250 . . .300 \mathrm{~m})$. We should mention that even with such characteristics they managed to eliminate the malaria hotspots. Though, since 1992, because of the lack of financing, the drain systems have not been cleaned which led to abrupt increase in waterlogged lands and appearance of marshes.

Due to the subsidies from the Republic state budget in 1998...2010 and the loan granted by the World Bank, the voluminous works were performed on cleaning and reconstructing the collector-drain systems due to which the area of waterlogged lands and number of watered settlements abruptly reduced, and finally, after 2006, there was not registered any case of malaria. It is worth mentioning that after draining the marshes on these areas which had not been salinized, the active salinization processes started. This phenomenon needs special attention. The open horizontal drains with such characteristics could not meet the current demands for the land's ameliorative conditions. Though, in comparison to the closed drains which operation is completely critical, the open drains at some extent significantly help to lower the level of groundwater if they are regularly cleaned from vegetation cover and silt deposits. It should be mentioned that open horizontal drains due they're not deep embedment fail to improve fundamentally the ameliorative condition of the valley, and to lower the level of groundwater to a such depth (here 2.5...3.0m) which will exclude water evaporation from them, and thus, land salinization. Besides, some open horizontal drains have technically not good characteristics, their operational efficiency becomes lower on those parts of the area where there are artificial dams and backwaters.

In order to irrigate crops on the country farms, on the open horizontal drains there are usually earth dams made through which the drain waters are reached to the soil surface. Every earth dam, like mentioned above, creates in the drain system $0.8 . .1 .5 \mathrm{~m}$ high backwater [6] which because of the spot small inclinations spreads quite far, at long distances, and waterlogs the adjacent area the size of which vary from 3 up to 10 ha depending on the backwater height. Building up of the backwaters on the drains causes the latter ones' quick alluviation and covering with vegetation. Considering the case, there exists also one condition that the owners of the plots ignore. In some places the drain waters contain a number of dangerous matters (alkali bicarbonates, sodium and magnesium chlorides, sulfates, heavy metals, etc.) which adversely affect the crops' productivity and cause the alkalization or salinization of the local lands. Creation of illegal earth dams on the Ararat valley is widespread, and, on the vast areas it makes the activities on improving the operation of at most poorly operating open drains wasted efforts. Generally, the wide spreadness of irrigation of drains by the backwaters can be explained by the fact that conveyance of other surface waters to the irrigated plots involves some technical and financial problems. It is also important to mention that in this case the water is used without corresponding payment.

In order to improve the productivity of open horizontal drains, it is necessary to eliminate the mentioned backwaters which is feasible only by providing other sources for irrigating the lands that locate under them. Our special surveys have found out that the prime alternative sources can be the local flowing wells the discharges of which are currently used partially or are not used at all. At most, if there are no such flowing wells nearby, the water can be supplied from the newly placed vertical wells by embedding them in the sub artesian aquifer. The appearance of large backwaters on the open drains is also caused due to the other numerous reasons, particularly due to the reducing pipes, bridges, sluices, infiltration basins of water pumping stations, high water levels in the water intakes, etc. Elimination of the backwaters surely will increase the productivity of the open drains and will help to reach the designed level of the groundwater. Significant works have been done in the framework of "Millennium Challenges" Project in order to eliminate the backwaters, including works on deepening, and cleaning the drain systems. Particularly on the Hrazdan-Araks collector, $6 \mathrm{~km}$ long section was cleaned, and on $18.2 \mathrm{~km}$ long section works on bed deepening works were performed. Besides, 26 water catchments were deepened which total length was about $48 \mathrm{~km}$, and 94 drains with $55 \mathrm{~km}$ total length. The depth of deepening in the sections varied within $0.5 \ldots 2.0 \mathrm{~m}$, and the thickness of the cleaned silt was 0.3...0.6m.

The State Budget financed the works of cleaning the open drains from vegetation and silt. As a result of those measures, in the Ararat valley a significant drawdown of the groundwater was observed. It is justified by the fact that in 2010 the area of waterlogged lands made up 16377 ha in comparison with the 30 996-ha registered in 1995. The present significantly large area of the waterlogged lands indicates the fact that the drain systems in the Ararat valley still cannot provide the required ameliorative favorable condition. Going further, we should mention that in future all open horizontal drains will be replaced by closed drains which as a rule should have their water withdrawing pumping stations in case, they will not have gravity withdrawal opportunity. It will help to save considerable financial means which at present are spent for cleaning the open drain system, and it will help to involve into crop rotation the closing vast additional areas. It is obvious that concurrently the closed horizontal drains clogged and silted up at present time should be reconstructed involving their water withdrawing pumping stations. It has been long time that "Amelioration" company of Water Committee has been implementing monitoring of groundwater levels in the Ararat valley. By using the results of the measurements let us study the regularities of regime fluctuation of levels for the groundwater allocated on the valley different typical parts. Manhole N409 is situated on the saline area of Masis district, at $20 \mathrm{~km}$ from the open horizontal drain. Here, the levels 
of the groundwater mainly depend on natural factors. The highest level of the groundwater is observed in spring months (IV and V), making up $0.5 \mathrm{~m}$ from the ground surface, when the precipitations are abundant, and the lowest level - in winter (XI and XII), the depth of embedment is $1.1 \mathrm{~m}$ (ref. Drawing 1). Such high level of the groundwater indicates also that this drain operates too badly.

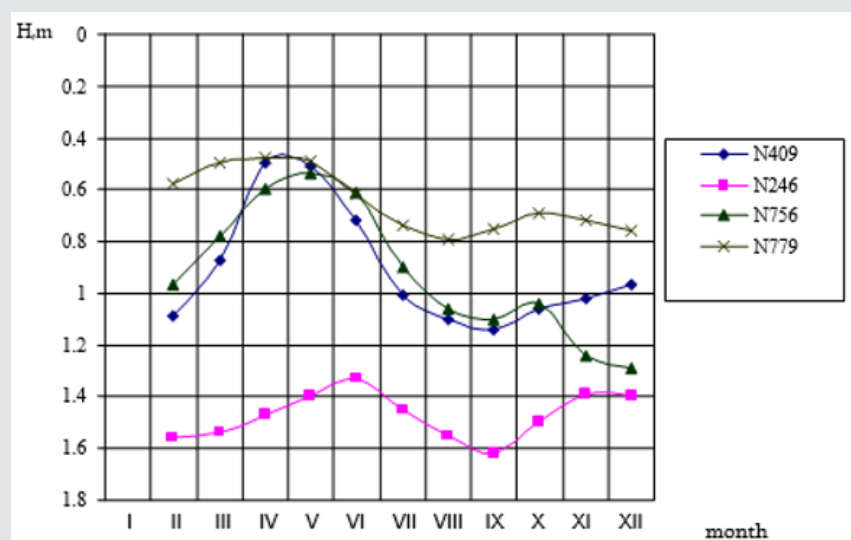

Figure 1: Groundwater annual fluctuations according salinized manholes N246, N409, N756 and N779.

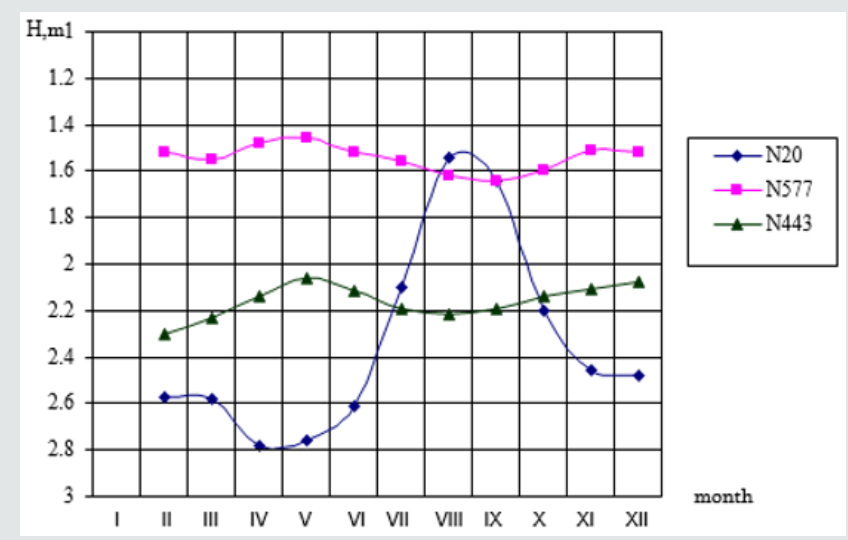

Figure 2: Annual fluctuations of groundwater according irrigated manholes N20, N443 and N577.

The same Figure 1 indicates that manhole N246 of Echmiadzin district and manhole N756 of Artashat district are in the same condition which are also allocated on the saline lands. According to these manholes, the annual fluctuation amplitude of the groundwater levels makes up $0.3 \ldots . .0 .6 \mathrm{~m}$. Manhole N 20 is situated on the irrigated lands of Masis district. Here the fluctuations of groundwater levels depend on the irrigation of lands. High levels are observed in vegetation period (especially in VII-VIII months), whereas in winter, the groundwater level gets closer to the natural condition (Figure 2). The fluctuation amplitude makes up $0.8 \mathrm{~m}$. The same regularity is observed in manhole N479 (Masis district), where the fluctuation amplitude is $0.6 \mathrm{~m}$, and in manhole N250 (Echmiadzin district), where the amplitude makes up $0.65 \mathrm{~m}$. The level of the groundwater is high especially on the areas adjacent to the fish farm ponds. It is well expressed in manhole N779 (Figure 1) (Ararat district, saline lands), where groundwater levels are at ground surface depending on the months of the year, merely at $0.5 \ldots . .0 .75 \mathrm{~m}$ depth. If the horizontal drains are not covered with vegetation and are not under the backwater, thus on their adjacent areas the groundwater are located on the comparatively deeper aquifers, and the amplitude of levels fluctuation is smaller. So, in Masis district manhole which is situated $8 \mathrm{~km}$ far from collector N6, the groundwater is located about $2.0 \mathrm{~m}$ deep from the ground surface, and fluctuation amplitude makes up $0.10 \mathrm{~m}$. In manhole N577, which is situated at $10 \mathrm{~m}$ distance from the Artashat district drains, the level of the groundwater is at average $1.5 \mathrm{~m}$ depth, and fluctuation amplitude makes up only 0.08 (Figure 2). This indicates that if the manholes had been located deeper and not with big spacing, the groundwater level could have been kept at the required depth.

\section{Conlusion}

a) The Ararat valley has poor natural self-draining ability, the closed horizontal drains built here are in critical condition, and open drains with their technically not favorable characteristics cannot provide the required drawdown of the groundwater levels. As a result, on the valley there are 16377 ha waterlogged plots and 26 watered settlements.

b) On the not irrigated (salinized) plots, the spring high level of groundwaters is observed, whereas in winter a drawdown is observed, the annual fluctuation amplitude makes up $0.4 \ldots 0.6 \mathrm{~m}$. On the irrigated plots the high level of groundwater is observed in summer months, and in not vegetation period it drawdowns. The fluctuation amplitude is $0.6 \ldots 0.8 \mathrm{~m}$. That regime of level fluctuations indicates that there is a big filtration of the irrigation waters. The very high and comparatively steady groundwater level is observed on the areas adjacent to the fish farm ponds.

On the areas adjacent to open horizontal drains which are in normal operating condition (cleaned from silt and vegetation), the groundwater level is close to the permissible, and it has small fluctuation amplitude $(0.08 \ldots 0.1 \mathrm{~m})$.

a) Implemented in the framework of "Millennium challenge" Project and and financed from the State Budget cleaning and deepening works significantly improved the ameliorative condition of thew Ararat valley (in comparison with 1995, the surface area of waterlogged lands reduced nearly twice, and number of watered settlements reduced 2.8 times).

b) In order to improve more the ameliorative condition, it is necessary to eliminate all backwaters existings in the open drain system, especially the earth dams built on the open drains to increase water in order to irrigate. In order to explain the further threat of soil pollution and salinization, the activities on raising the population awareness should be performed among the locals.

c) In future, to improve fundamentally the Ararat valley ameliorative condition, it is necessary to replace open drains with unfavorable technical characteristics by the closed ones mandatory providing with water withdrawing structures and facilities without backwaters, and the clogged closed systems should be completely reconstructed. 


\section{References}

1. (2009) Cadastre of meliorative condition of irrigated and dried land in the Republic of Armenia. Melioration CJSC, Ministry of Territorial Management of Republic of Armenia, State Committee of Water Supply, pp. 201.

2. MG Bos (1994) Subsurface Drainage Systems. In: HP Ritzema (Eds.), Drainage Principles and Applications, ILRI Publication International Institute for Land Reclamation and Improvement (ILRI), Wageningen, Netherlands 16: 725-798.

3. Fetter CW (1994) Applied Hydrology, Third Edition. Prentice-Hall, Inc., New Jersey, USA, pp. 691.
4. Melikian NL (1995) Study the current working status of the Ararat valley horizontal drainage and to develop measures to increase their efficiency, Scientific Report, Institute of Water Problems and Hydraulic Engineering, p. 40.

5. Melikian NL (1997) The problem of drainage systems in Ararat valley. Agrogitutyun 3-4: 202-209.

6. Melikian NL, Aloyan NG, Tadevosian VT (2008) About backwaters in the open horizontal drainage of the Ararat valley, Proceedings of the international scientific conference Ecological problems of agriculture, Yerevan, Bulletin of SAUA, p. 87-92.

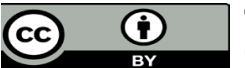

This work is licensed under Creative Commons Attribution 4.0 License

To Submit Your Article Click Here: Submit Article

DOI: $10.32474 /$ CIACR.2019.06.000240

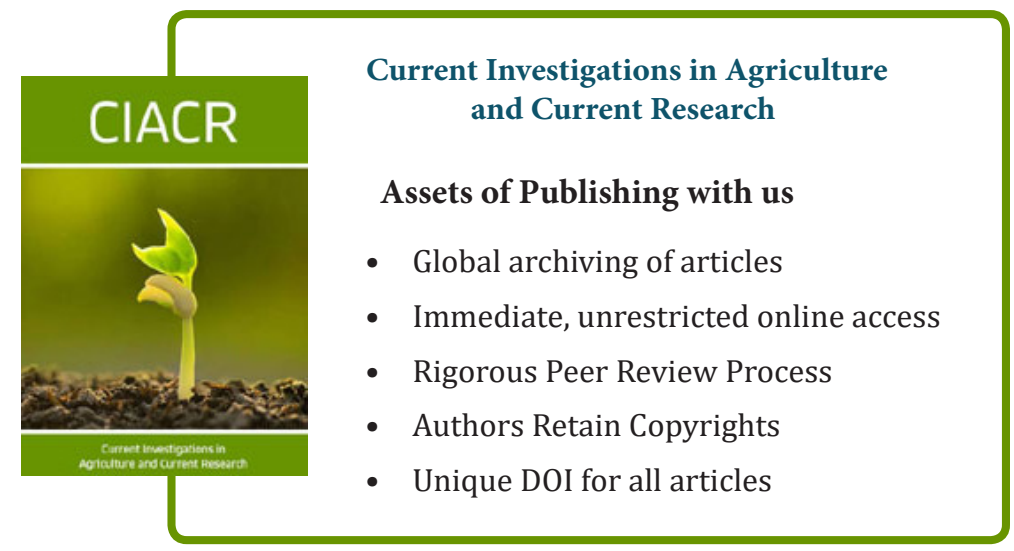

